\title{
Merja Polvinen
}

\section{Innovaatio Euroopassa - nyhjää tyhjästä? Keskustelu Monika Fludernikin kanssa}

Freiburgin yliopiston englannin kielen ja kirjallisuuden professori Monika Fludernik on monella tapaa ainutlaatuisessa asemassa puhumaan kirjallisuudenopetuksen ja -tutkimuksen tulevaisuudesta eurooppalaisissa yliopistoissa. Hänen oma uransa tutkijana kattaa niin kirjallisuuden- kuin kielentutkimuksen, kuten käy ilmi esimerkiksi teoksista The Fictions of Language and the Languages of Fiction. The Linguistic Representation of Speech and Consciousness (1993) ja Towards a 'Natural' Narratology (1996). Professori Fludernik on ollut akateemisessa virassa useiden eri maiden yliopistoissa sekä luottamustehtävissä kansainvälisissä järjestöissä. Mutta erityisesti viimeisten kahdeksan vuoden ajan hän on ollut aitiopaikalla arvioidessaan yhtäältä tutkimusprojekteja Saksan Akatemian (Deutsche Forschungsgemeinschaft) rahoituspäätöksiä varten ja toisaalta Helsingin yliopiston tutkimus- ja opetustoimintaa Tutkijakollegiumin johtoryhmän (Academic Advisory Board) ja Humanistisen tiedekunnan laitoksiin tutustuneen kansainvälisen arviointiryhmän jäsenenä.

Vuonna 2005 Fludernik julkaisi New Literary History -aikakausijulkaisussa artikkelin otsikolla "Threatening the University - The Liberal Arts and the Economization of Culture". Artikkeli on perinteisen yliopistoideaalin puolustus, unohtamatta kuitenkaan uuden maailman mukanaan tuomia vaatimuksia ja mahdollisuuksia. Oppimiseen ja tutkimiseen perustuvan yliopistoinstituution tämänhetkinen ahdinko on Fludernikin mukaan seurausta siitä, että yksi valistuksen ajan keskeisistä ajatuskomplekseista - edistysmielisyys, utilitarismi ja pragmaattinen filosofia - on haudannut alleen toisen saman aikakauden keskeisen ideaalin - humboldtilaisen sivistysyliopiston. ”Tulosajattelu on ajanut yliopistot tilaan, jossa sijoitukselle odotetaan tuottoa ja panostuksesta tuloksia hyvinkin nopeasti. Tästä syystä soveltavista tieteistä on tullut koko yliopistomaailman mittari."

Vaikka hyväksyttäisiinkin ajatus siitä, että yliopistojärjestelmän on tarkoitus tuottaa jotakin, vallitsee Euroopassa tällä hetkellä käsittämätön epäsuhta sijoitusten ja odotettujen tulosten välillä. "Suurin ongelma Euroopan maiden hallitusten ja yliopistojen välillä tällä hetkellä on se, että poliitikot olettavat, että Nobel-palkintoja voidaan tuottaa järjestelmästä, jonka rahoitus on vain murto-osa amerikkalaisten huippuyliopistojen 
käytössä olevista resursseista”, Fludernik toteaa. Nykypuheet innovaatioista ja huippuyliopistoista tulevat jäämään vain puheeksi niin kauan, kun eurooppalaisten yliopistojen odotetaan venyvän joka suuntaan. "Opiskelijamäärät ovat räjähtäneet myös Saksassa. Omalla laitoksellani on yhteensä 2000 opiskelijaa ja opintojen loppuvaiheessa olevia ohjaa kaksi brittiläisen kirjallisuuden ja kaksi amerikkalaisen kirjallisuuden professoria, sekä kaksi lingvistiikan professoria. Itselläni on ohjauksessa noin neljäkymmentä maisterintutkielmaa ja näiden lisäksi kuulustelen suullisesti joka lukukauden aikana kolmekymmentäviisi valmistuvaa opiskelijaa”. Opiskelijamäärien takana on Fludernikin mielestä vääristynyt ajatus demokraattisesta yhteiskuntamallista. ”Pyrkiessään kouluttamaan vähintään viisikymmentä prosenttia joka sukupolvesta maisteriksi asti, yhteiskunta luottaa elitismin vastaiseen mutta aivan takaperoiseen ajatukseen siitä, että kaikilla yhteiskunnan jäsenillä tulisi olla sama koulutustaso”, Fludernik toteaa artikkelissaan. Suomea hän kehuu juuri siitä, että koulutus on ilmaista, mutta sitä ei jaeta kaikille, vaan yliopistoon päästäkseen opiskelijan tulee osoittaa tietty perustaso ja kyky omaksua uutta tietoa.

Tapaan, jolla rahoitusta jaetaan korkealle tähtäävien tutkimusinstituutioiden ja opetukseen keskittyvien yliopistojen kesken Fludernik suhtautuu kuitenkin epäillen. "Saksassa käyttöönotettu järjestelmä, jossa kilpaillaan viisivuotisesta huippuyliopistostatuksesta, on erittäin lyhytnäköinen. Ajatuksena on, että rahoituksen saanut yliopisto voi palkata laitoksilleen lisää huippuosaajia ja siten erinomaiset tulokset jatkuisivat erityisrahoituksen päätyttyäkin, mutta moinen ei ota huomioon virkojen puutetta. Oma laitokseni ei voi tarjota uutta professuuria ennen kuin joku meistä lähtee eläkkeelle. Joten erityisrahalla palkatut huippuosaajat katoavat viiden vuoden kuluttua, jos heitä niin lyhytaikainen rahoitus edes alun perinkään kiinnostaisi.”

Rahoituksen määrän ja jatkuvuuden lisäksi ongelmana on Fludernikin mielestä se oletus, että monitieteisyys on arvo sinänsä. "Saksan Akatemian huippustatushaussa rahaa voivat hakea vain monitieteiset projektit, eikä perustutkimukselle jonkin tietyn tutkimusparadigman sisällä myönnetä lainkaan tukea. Tämä on luonnollisesti ongelma erityisesti humanistisille tieteille, joissa suurin osa huippututkimuksesta tehdään siten, että yksi tutkija saa erinomaisen, ainutlaatuisen ajatuksen, työstää sitä useita vuosia ja julkaisee lopulta monografian, joka saa koko maailman haukkomaan henkeään. Tutkimusrahoituksen nykymuodot on suunniteltu luonnontieteitä ajatellen, eivätkä omia polkujaan kulkevat humanisti-innovaattorit välttämättä löydä projektirahoitukseen tarvittavia verkostoja. Sitä paitsi yhteistyö eri tutkimuskenttien välillä tarvitsee yleensä vakiintuneen metodologisen pohjan, jolle kaikki voivat yhdessä rakentaa, kun taas humanistisissa tieteissä metodologian kyseenalaistaminen ja kehittäminen on välttämätön osa itse tutkimuksen tekoa." Ei monitieteisyys ole Fludernikin mielestä tietenkään itsessään pahasta - hänen oma tutkimuksensa on ylittänyt kirjallisuuden- ja kielentutki- 
muksen rajoja jo vuosien ajan - mutta humanistisissa tieteissä monitieteiset projektit tuottavat yleensä lähinnä mielenkiintoisia lisähuomioita ja uudelleenarviointeja. Niitä on ehkä helpompi markkinoida tiedemaailman ulkopuolella, mutta todelliset läpimurrot tehdään muualla.

Maisterintutkintojen määrän kasvu on näkynyt tietenkin myös väitöskirjantekijöiden määrän moninkertaistumisena. Fludernik toivoo kuitenkin, että Euroopassa pystytään pitämään kiinni korkeista standardeista. "Saksalainen kirjallisuusväitöskirja ei enää ole 800-sivuinen ja hyvä niin! Mutta on tietenkin huoli siitä, että vaatimukset kevenevät liikaa. Tämä huoli liittyy eritoten hallituksen ja tutkimusrahoittajien vaatimuksiin siitä, että väitöskirjan on valmistuttava kolmessa vuodessa. Humanistisilla ja eritoten tulkintaan perustuvilla aloilla ei kuitenkaan päästä yli eikä ympäri siitä, että tutkimuskirjallisuuteen tutustumiseen ja hyvän aiheen löytämiseen menee vuosi ja vasta siinä vaiheessa voi jatko-opiskelija elättää toiveita hyvän rahoitushakemuksen kirjoittamisesta. Ongelmaa on yritetty ratkaista siten, että jo maisterintutkielmaa kirjoittaessa tähdätään sellaiseen aiheeseen, jota voi laajennettuna käyttää väitöskirjan aiheena: yhden kirjailijan rinnalle otetaan useita, historiallinen perspektiivi luodaan laajentamalla aineistoa 1900-luvulta 1800-luvulle tai muuta sellaista. Oletusarvona on tietenkin se, että tutkielman metodologinen ote on jo maisterivaiheessa erinomainen ja vain kaikkein parhaiden maistereiden annetaan jatkaa väitöskirjaan asti. Toinen ratkaisumalli olisi se, että ohjaajat ottaisivat paljon enemmän vastuuta aiheen ja tutkimuskirjallisuuden valinnassa, kuten englantilaisissa yliopistoissa on tehty."

Saksassa käytössä oleva habilitation eli väitöksen jälkeinen, toinen tutkimusnäyte saa Fludernikiltä myös tukea, vaikkakin sen olemassaolon syyt ovat osin idealistiset. "Vaatimus siitä, että professorin virkaan astuvalla tutkijalla on näyttöä tutkimustyöstä ainakin kahdella eri alueella, esimerkiksi eri periodeista tai eri kirjallisuudenlajeista, on erittäin tärkeää silloin, kun laitokset ovat suhteellisen pieniä eivätkä professorit voi opinnäytteitä ohjatessaan keskittyä vain omaan, kapeaan tutkimussektoriinsa. On tietenkin myönnettävä, ettei kukaan voi tietää kaikkea, ja että eurooppalaiset tutkijat joutuvat aina myöntämään, etteivät he voi tuntea jotakin tiettyä tutkimusalaa ehkä yhtä syvällisesti kuin brittiläiset ja amerikkalaiset kollegansa, jotka ovat kandidaatintutkintonsa jälkeen tutkineet vain sitä yhtä ja samaa asiaa.” Toisen kirjan vaatimusta on yritetty häivyttää joissain päin Saksaa, mutta huonoin tuloksin. "Laitoksille on luotu apulaisprofessorin virkoja, joiden on tarkoitus korvata habilitation, mutta ne on aina määritelty hyvin tarkkaan tietyn tutkimusalueen viroiksi - vaikkapa postkolonialistiseen kirjallisuuteen tai keskiaikaan erikoistuneelle tutkijalle - koska laitoksella kaivataan osaamista juuri tietyllä alueella. Tällöin vastaväitellyt viransaaja ei päädy laajentamaan tutkimuskenttäänsä lainkaan. Tämä kostautuu viiden tai kuuden vuoden kuluttua, kun hän hakee professorin virkaa ja saa huomata, että niihin laitokset haluavat laaja-alaista osaamista, 
eivätkä yhden alan eksperttiä.”

Suomalaisen yliopistoverkoston Fludernik toteaa muistuttavan monin tavoin saksalaista vastinettaan. ”Toivottavasti ette täällä joudu käymään läpi niitä samoja taisteluita, joita meillä käydään: esimerkiksi opettajankoulutus on yritetty siirtää kokonaan pois yliopistoista ja vaikka se epäonnistui, on yliopistojen opetusohjelmaan sisällytetty valtava määrä pedagogisia opintoja sisällön kustannuksella." Yliopistojen välille on myös koetettu väen vängällä luoda tasoeroja yli tieteenalojen. "Rahaa annetaan niille yliopistoille, joilla sitä ja menestystä on, huolimatta siitä, onko niiden edustama tutkimusparadigma jo käytössä kulunut. Tällainen järjestelmä ei rohkaise uutta, todella innovatiivista tutkimusta, eikä niitä tutkijoita, joiden ajatukset käyvät eri tahtiin hallitsevan paradigman kanssa.”

Monika Fludernik vieraili Erasmus-vaihdon puitteissa Helsingin yliopiston englannin kielen laitoksella hubtikuussa 2007. 